Calculations of current densities for neutral and doubly charged persubstituted benzenes using effective core potentials

\title{
Rauhalahti, Markus
}

2017-03-14

Rauhalahti , M , Taubert , S, Sundholm , D \& Liegeois, V 2017 , ' Calculations of current densities for neutral and doubly charged persubstituted benzenes using effective core potentials ' , Physical Chemistry Chemical Physics , vol. 19 , no. 10 , pp. 7124-7131 . https://doi.org/10.1039/c7cp00

http://hdl.handle.net/10138/307921

https://doi.org/10.1039/c7cp00194k

acceptedVersion

Downloaded from Helda, University of Helsinki institutional repository.

This is an electronic reprint of the original article.

This reprint may differ from the original in pagination and typographic detail.

Please cite the original version. 


\section{Journal Name}

\section{ARTICLE TYPE}

Cite this: DOI: 10.1039/xxxxxxxxxx

\author{
Accepted Date \\ DOI: $10.1039 / x x x x x x x x x x$ \\ www.rsc.org/journalname \\ Received Date \\ whisc.org/journathame
}

\section{Calculations of current densities for neutral and dou- bly charged persubstituted benzenes using effective core potentials ${ }^{\dagger}$}

\author{
Markus RAUHALAHTI, ${ }^{a}$ Stefan TAUBERT, ${ }^{* a}$ Dage SUNDHOLM, ${ }^{a}$ and Vincent \\ LIÉGEOIS ${ }^{b}$
}

\begin{abstract}
Magnetically induced current density susceptibilities and ring-current strengths have been calculated for neutral and doubly charged persubstituted benzenes $\mathrm{C}_{6} \mathrm{X}_{6}$ and $\mathrm{C}_{6} \mathrm{X}_{6}{ }^{2+}$ with $\mathrm{X}=\mathrm{F}, \mathrm{Cl}, \mathrm{Br}$, I, At, $\mathrm{SeH}, \mathrm{SeMe}, \mathrm{TeH}, \mathrm{TeMe}$, and $\mathrm{SbH}_{2}$. The current densities have been calculated using the gauge-including magnetically induced current (GIMIC) method, which has been interfaced to the Gaussian electronic structure code rendering current density calculations using effective core potentials (ECP) feasible. Relativistic effects on the ring-current strengths have been assessed by employing ECP calculations of the current densities. Comparison of the ring-current strengths obtained in calculations on $\mathrm{C}_{6} \mathrm{At}_{6}$ and $\mathrm{C}_{6} \mathrm{At}_{6}{ }^{2+}$ using relativistic and non-relativistic ECPs show that scalar relativistic effects have only a small influence on the ring-current strengths. Comparisons of the ring-current strengths and ring-current profiles show that the $\mathrm{C}_{6} \mathrm{I}_{6}{ }^{2+}, \mathrm{C}_{6} \mathrm{At}_{6}{ }^{2+}, \mathrm{C}_{6}(\mathrm{SeH})_{6}{ }^{2+}$, $\mathrm{C}_{6}(\mathrm{SeMe})_{6}{ }^{2+}, \mathrm{C}_{6}(\mathrm{TeH})_{6}{ }^{2+}, \mathrm{C}_{6}(\mathrm{TeMe})_{6}{ }^{2+}$, and $\mathrm{C}_{6}\left(\mathrm{SbH}_{2}\right)_{6}{ }^{2+}$ dications are doubly aromatic sustaining spatially separated ring currents in the carbon ring and in the exterior of the molecule. The $\mathrm{C}_{6} \mathrm{I}_{6}{ }^{+}$radical cation is also found to be doubly aromatic with a weaker ring current than obtained for the dication.
\end{abstract}

\section{Introduction}

Oxidation of hexaiodobenzene $\left(\mathrm{C}_{6} \mathrm{I}_{6}\right)$ with $\mathrm{Cl}_{2}$ or $\mathrm{H}_{2} \mathrm{O}_{2}$ yielded a stable salt without any electron spin resonance (ESR) signal suggesting that a $\mathrm{C}_{6} \mathrm{I}_{6}{ }^{2+}$ dication with a singlet ground state was obtained in the synthesis, ${ }^{1}$ whereas similar experiments on $\mathrm{C}_{6} \mathrm{Cl}_{6}$ yielded a $\mathrm{C}_{6} \mathrm{Cl}_{6}{ }^{2+}$ dication in the triplet state as judged from ESR measurements. ${ }^{1,2}$ The closed-shell $\mathrm{C}_{6} \mathrm{I}_{6}{ }^{2+}$ dication was found to exhibit $\sigma$ delocalisation between the iodine atoms. ${ }^{1} \mathrm{~A}$ milder oxidation of $\mathrm{C}_{6} \mathrm{I}_{6}$ using $\mathrm{SbF}_{5}$ or $\mathrm{AsF}_{5}$ yielded a salt containing the $\mathrm{C}_{6} \mathrm{I}_{6}{ }^{+}$radical dication, which has as $\mathrm{C}_{6} \mathrm{I}_{6}{ }^{2+}$ an undistorted hexagonal molecular structure. ${ }^{3,4}$

Theoretical studies on the $\mathrm{C}_{6} \mathrm{I}_{6}{ }^{2+}$ dication suggested that the electron density is delocalised between the iodine atoms form-

\footnotetext{
a Department of Chemistry, University of Helsinki, P.O.Box 55, FIN-00014 Helsinki, Finland.; E-mail: staubert@chem.helsinki.fi

${ }^{b}$ Laboratoire de Chimie Théorique (LCT), Unité de Chimie-Physique Théorique et Structurale (UCPTS), University of Namur, Rue de Bruxelles, 61, B-5000 Namur, Belgium.; E-mail: vincent.liegeois@unamur.be

$\dagger$ Electronic Supplementary Information (ESI) available: The transformation of density matrices expressed in real spherical-harmonic basis sets to density matrices in Cartesian basis sets is described in detail. The Cartesian coordinates of the studied molecules are reported. See DOI: 10.1039/b000000x/
}

ing a $\sigma$ ring that sustains a ring current leading to a doubly aromatic character with one ring current in the carbon framework and an outer ring current between the halogen atoms. ${ }^{5,6}$ Due to steric repulsion, the $\sigma$ orbitals in $\mathrm{C}_{6} \mathrm{I}_{6}$ are shifted up in energy becoming the highest occupied molecular orbital (HOMO), the electrons of which disappear upon oxidation. Perhalogenated benzenes with halogens lighter than iodine have a different electronic structure, because the size of the lighter halogens leads to a smaller overlap of the $p_{\sigma}$ orbitals of adjacent halogens. For the lighter perhalogenated benzenes and benzene, the $p_{\pi}$ orbitals of the carbons form the HOMO. Thus, doubly oxidation of the lighter perhalogenated benzenes is expected to result in an open-shell species with a triplet ground state. The aromatic character of isoelectronic benzenes with six main-group substituents have been studied computationally by Hatanaka et al. to assess whether the corresponding doubly ionised benzenes sustain a $\sigma$ ring current along the outer edge of the dication. ${ }^{7}$ Nucleus independent chemical shift (NICS) calculations showed that some of the investigated dications sustain a stronger ring current than benzene as judge from the calculated NICS values. ${ }^{7}$ Ciofina et al. investigated computationally the $\sigma$ delocalisation and degree of aromaticity of $\mathrm{C}_{6} \mathrm{I}_{6}, \mathrm{C}_{6} \mathrm{Cl}_{6}$, and the corresponding dications by calculating nu- 
clear magnetic resonance (NMR) chemical shifts and NICS values. ${ }^{5}$ Havenith et al. studied the electron delocalisation and ring currents using current density mappings via the ipsocentric approach and a multi-center delocalisation index. ${ }^{6}$ NICS values are an indicator of the magnetic response providing indirect information about the magnetically induced ring current, whereas current density plots provide a qualitative picture of the current flow.

The aim of this work is to calculate the magnetically induced current density of the persubstituted benzenes using the gaugeincluding magnetically induced current (GIMIC) method. ${ }^{8-10}$ The ring current pattern in persubstituted benzenes and their dications forms one or two separated ring currents implying that a more detailed analysis of the ring current is needed for understanding the current flow around the molecular ring. Numerical integration of the current density passing selected planes intersecting the molecular ring yields current-strength susceptibility (in $\mathrm{nA} / \mathrm{T}$ ) and ring current profiles, whereas visualisation of current densities provides qualitative information about the current density flow. In the following, we use the shorter current strength instead of current-strength susceptibility.

The degree of aromaticity can be estimated from the strength of the ring current. Aromatic ring-shaped molecules sustain a net diatropic ring current when they are exposed to an external magnetic field. ${ }^{11-13}$. The ring current generally consists of diatropic and paratropic contributions flowing in opposite directions. For aromatic molecules the diatropic component flowing in the classical direction dominates, whereas molecules with predominant paratropic ring current are antiaromatic. In nonaromatic molecules, the diatropic and paratropic components are practically equal leading to a vanishing net ring-current strength. Calculated ring-current strengths can be used as a quantitative measure of the aromaticity of similar molecular rings, whereas when comparing the ring-current strengths of molecules with different number of electrons and size of the molecular ring, the ringcurrent strength provides qualitative information about the aromaticity. The archetypical aromatic compound benzene, whose calculated ring-current strength at the B3LYP/def2-TZVP level is $11.8 \mathrm{nA} / \mathrm{T},{ }^{14}$ can be used as reference.

The GIMIC method ${ }^{8-10}$ has been implemented in an independent computer program that uses the unperturbed and the perturbed electron density matrices as well as basis-set information as input data. The density matrices are obtained when calculating NMR magnetic shieldings using standard quantum chemistry programs. GIMIC calculations are completely independent of the employed computational level, because the information about the level of the electronic structure calculation is contracted into the density matrices.

The NMR shielding tensor of open-shell molecules consists of the orbital, Fermi-contact, and dipolar contributions. ${ }^{15}$ NMR shielding calculations on open-shell molecules yield separate unperturbed and perturbed density matrices for $\alpha$ and $\beta$ electrons. The hyperfine Fermi-contact and the dipolar terms do not have any direct reference to the external magnetic field. Thus, they do not contribute to the first-order expression for calculating magnetically induced current densities. Hence, only the orbital contribution to the NMR shielding tensor has to be taken into account when calculating current densities for open-shell systems as previously discussed. ${ }^{9}$ The total current strength is the sum of $\alpha$ and $\beta$ contributions, whereas the spin current is obtained as the difference between them.

GIMIC calculations can be performed at any level of theory using output data from most quantum chemistry programs provided that the density matrices are made available in the required format. Thus, a code interface has to be written for every quantum chemistry program. GIMIC has previously been interfaced to Turbomole ${ }^{16,17}$ and CFOUR ${ }^{18}$ rendering all-electron current density calculations at the density functional theory (DFT) and $a b$ initio levels of theory feasible. Closed-shell calculations at the DFT, Hartree-Fock (HF), and second-order Møller-Plesset perturbation theory (MP2) levels can be performed with Turbomole, whereas CFOUR renders in addition current density calculations at coupled cluster singles and doubles (CCSD) level and coupled cluster singles and doubles level with a perturbative treatment of the triples CCSD(T) feasible. CFOUR can be used for calculating current densities for open-shell molecules at the HF, MP2, and CCSD levels. Thus, so far it has not been possible to study current densities of open-shell molecules at the DFT level using GIMIC. It has not been possible to perform GIMIC calculations in combination with effective core potentials (ECP) either. In this work, we have adapted GIMIC to the Gaussian electronic structure code. Current density calculations are now possible at all levels of theory that can be employed in calculations of NMR magnetic shieldings with Gaussian.

In this work, we calculate ring-current pathways and ringcurrent strengths of a series of persubstituted benzenes, including the halogens from $\mathrm{F}$ to At, where I and At require the usage of ECPs for considering scalar relativistic effects. Dications of persubstituted benzenes with substituents from the main groups 15 and 16 of the periodic table are also studied. The substituents are $\mathrm{SeH}, \mathrm{SeMe}\left(\mathrm{Me}=\right.$ methyl), $\mathrm{TeH}, \mathrm{TeMe}$, and $\mathrm{SbH}_{2}$. Current density calculations on molecules containing heavier elements than Te are the first ones with GIMIC in combination with ECPs. The implementation of the Gaussian-GIMIC interface is briefly presented.

\section{Computational Methods}

The molecular structure optimisations, single-point energy calculations, and NMR magnetic shielding calculations for molecules with all atoms lighter than tellurium were performed at the B3LYP ${ }^{19,20}$ level using version 6.5 of Turbomole and the def2TZVP basis sets. ${ }^{16,21-25}$ For molecules containing tellurium and heavier elements, the quasi-relativistic def2-ECP was used to account for scalar relativistic effects. ${ }^{25}$ All structure optimisations were performed without any symmetry constraints. The optimised structures do not have any imaginary vibrational frequencies. The Cartesian coordinates of the optimised structures are reported in the Electronic Supplementary Information (ESI).

The NMR magnetic shielding calculations were performed with Gaussian09 at the same level of theory and using the same basis sets as used in the geometry optimisation. ${ }^{26} \mathrm{~A}$ set of test calculations with different density functionals as well as at the Hartree-Fock level was performed in order to assess the 
effect of the amount of exact Hartree-Fock exchange on the ring-current strengths. The investigated functionals were BP86 $(0 \%),{ }^{27,28}$ PBE (0\%), ${ }^{29,30}$ BLYP (0\%), ${ }^{31}$ B3LYP (20\%), ${ }^{27,31,32}$ PBEO (25\%), ${ }^{29,30,33}$ and BHLYP (50\%), ${ }^{27,31,34}$ where the amount of exact exchange is in given within parenthesis.

The role of the scalar relativistic effects was investigated for neutral and dicationic $\mathrm{C}_{6} \mathrm{I}_{6}$ and $\mathrm{C}_{6} \mathrm{At}_{6}$ using the Stuttgartfamily ECPs. ${ }^{35}$ For iodine, the fully relativistic ECP28MDF ${ }^{36}$ and the quasi-relativistic ECP46MWB ${ }^{37}$ were employed. For astatine, the fully relativistic ECP78MDF ${ }^{38}$ and the non-relativistic ECP78MHF ${ }^{39}$ were employed. The number in the acronyms refers to the number of electrons considered by the ECP. The corresponding double-zeta (DZ), triple-zeta (TZ), and quadruplezeta (QZ) valence basis sets were used. ${ }^{35}$ For I, the TZ and QZ valence basis sets by Peterson et al. were used in combination with ECP28MDF, ${ }^{40}$ whereas the TZ and QZ valence basis set by Martin and Sunderman were used with ECP46MWB. ${ }^{36}$ For At, the DZ valence basis set by Kuechle et al. was used with ECP78MHF, ${ }^{41}$ whereas the DZ valence basis set for ECP78MDF was optimised by Stoll et al. ${ }^{38}$ An all-electron calculation was also performed for $\mathrm{C}_{6} \mathrm{I}_{6}{ }^{2+}$ using the iodine ATZP basis set by Martins et al. ${ }^{42}$ In the ECP calculations, the def2-TZVP basis set was used for carbon. ${ }^{25}$

Current densities (susceptibilities) and ring-current (susceptibility) strengths were calculated with GIMIC. ${ }^{8-10}$ The magnetic field was oriented perpendicular to molecular plane defined by the carbon framework, which was planar in all studied compounds. Integration of the current density was performed on a plane perpendicularly to the molecular plane and parallel to the applied magnetic field. The plane begins at the center of the benzene ring and reaches 5 bohr outside the molecule in the two directions. The current gradient profile $\frac{d J}{d x}$ across the chemical bond is obtained by calculating differential contributions to the current strength $J$ along an axis $x$ perpendicularly to the bond.

The isotropic nucleus independent chemical shift has been calculated in the center of the ring (NICS(0)) and the $z z$ component (NICS $(1)_{z z}$ ) one $\AA$ above the center of the ring to calculate the magnetic response that yields an estimate for the ring-current strength. ${ }^{43,44}$

The Figures have been made using DrawMol program. ${ }^{45}$

\subsection{Interfacing GIMIC to Gaussian}

The density matrices for the GIMIC program are obtained by performing NMR shielding calculations using an electronic structure code. The density matrices obtained using the Gaussian program are transformed into the appropriate format by using the GAUSSIAN2gimic.py program written in python. In that program, the matrix elements of the density matrices in the atomic orbital (AO) basis are reordered and transformed from real spherical-harmonic AOs to Cartesian AOs that are used in GIMIC. The transformation of the density matrices from spherical AO basis to Cartesian AO basis is: ${ }^{46,47}$

$$
D_{p q}^{\text {Cartesian, CGTO }}=\sum_{\mu v} c_{p \mu} c_{q v}^{*} D_{\mu v}^{\text {Spherical,CGTO }}
$$

where $c_{p \mu}$ are the transformation coefficients, whose expression is derived in detail in the Electronic Supplementary Information (ESI).

\section{Calculations on $\mathrm{C}_{6} \mathrm{X}_{6}$ and $\mathrm{C}_{6} \mathrm{X}_{6}{ }^{2+}, \mathrm{X}=\mathrm{F}, \mathrm{Cl}$, $\mathrm{Br}$, I, and At}

\subsection{Method comparison}

Current density calculations using the B3LYP functional in combination with triple-zeta quality basis sets have previously been found to yield a ring-current strength for benzene that agrees well with the ones calculated at the $\operatorname{CCSD}(\mathrm{T})$ level. ${ }^{8}$ The ringcurrent strengths for benzene $\left(\mathrm{C}_{6} \mathrm{H}_{6}\right)$ and for the hexaiodobenzene dication $\left(\mathrm{C}_{6} \mathrm{I}_{6}{ }^{2+}\right)$ were calulated using a number of density functionals at the generalized gradient approximation (GGA) as well as by using hybrid functionals. Hybrid functionals with varying amount exact exchange were chosen to assess its influence on the calculated current densities. The obtained ring-current strengths are summarized in Table 1 . The calculations show that increasing the amount of exact exchange increases the strength of the ring current. For benzene, the paratropic contribution to the ring current is practically independent of the employed functional, whereas the diatropic contribution increases with increasing amount of exact exchange. The diatropic contribution is $2.2 \%, 4.8 \%$, and $8.9 \%$, larger at the B3LYP, BHLYP, and HF level, respectively than obtained using the BLYP functional without any HF exchange. For the paratropic contribution, the corresponding differences with respect to BLYP are $6.1 \%, 8.1 \%$, and $8.1 \%$. For the dication $\mathrm{C}_{6} \mathrm{I}_{6}{ }^{2+}$, the paratropic contribution is more dependent on the amount of exact exchange. The diatropic component is $4.7 \%, 11.2 \%$, and $21.3 \%$ larger at the B3LYP, BHLYP, and HF levels, as compared to BLYP, while for the paratropic component the corresponding numbers are $2.2 \%, 5.0 \%$, and $9.8 \%$. The comparison shows, that there is not a very large difference in the current strengths obtained using the hybrid functionals. The B3LYP/def2-TZVP level is chosen in this work.

\subsection{Perhalogenated benzene}

The calculated ring-current strengths and NICS values for the neutral perhalogenated benzenes are listed in Table 2. The ring current flows mainly along the carbon ring in the perhalogenated molecules and the current strength is $2-4 \mathrm{nA} / \mathrm{T}$ weaker than in benzene. For the molecules with heavier halogens, the current strength is somewhat weaker than for $\mathrm{C}_{6} \mathrm{~F}_{6}$, which sustains a ring current that is $2.3 \mathrm{nA} / \mathrm{T}$ weaker than benzene as also obtained in a previous computational studies on perfluorenated polyaromatic hydrocarbons by Kaipio at al. ${ }^{48}$ and on perfluorenated benzene by Torres-Vega et al. ${ }^{49}$ Since fluorine is the most electronegative and electron withdrawing element among the halogens, one would expect that perfluorinated benzene has the weakest ringcurrent. However, the calculations do not yield the expected trend as seen in Table 2. $\mathrm{C}_{6} \mathrm{~F}_{6}$ sustains a weaker diatropic contribution to the ring current than the heavier perhaloginated benzenes as one would expect based on the electronegativity of the halogens, whereas the strength of the paratropic contribution to the ring current increases faster with increasing atomic number than 
Table 1 The paratropic and diatropic contributions and the net magnetically induced ring-current strengths (in $\mathrm{nA} / \mathrm{T}$ ) calculated for benzene and the hexaiodobenzene dication at the HF and DFT levels using different exchange correlation functionals. The amount of exact exchange $\left(X_{H F}\right.$, in \%) is also given.

\begin{tabular}{llcccc}
\hline Molecule & Functional & $\mathrm{X}_{\mathrm{HF}}$ & Total & Dia & Para \\
\hline $\mathrm{C}_{6} \mathrm{H}_{6}$ & PBE & 0 & 11.67 & 16.67 & -5.00 \\
& BP86 & 0 & 11.72 & 16.70 & -4.99 \\
& BLYP & 0 & 11.65 & 16.58 & -4.93 \\
& B3LYP & 20 & 11.97 & 16.94 & -4.96 \\
& PBE0 & 25 & 12.07 & 17.10 & -5.03 \\
& BHLYP & 50 & 12.41 & 17.38 & -4.97 \\
& HF & 100 & 13.08 & 18.05 & -4.97 \\
\hline $\mathrm{C}_{6} \mathrm{I}_{6}{ }^{2+}$ & PBE & 0 & 26.12 & 29.73 & -3.61 \\
& BP86 & 0 & 27.21 & 30.87 & -3.66 \\
& BLYP & 0 & 25.91 & 29.49 & -3.58 \\
& B3LYP & 20 & 27.21 & 30.87 & -3.66 \\
& PBE0 & 25 & 27.75 & 31.45 & -3.70 \\
& BHLYP & 50 & 29.03 & 32.79 & -3.76 \\
& HF & 100 & 31.84 & 35.77 & -3.93 \\
\hline
\end{tabular}

the diatropic one decreases, leading to a weaker net ring current strength for the heavier perhalogenated benzenes.

The ring current is split into three contributions. A paratropic ring current flows inside the benzene ring. The main diatropic current circulates around the carbon ring and a small paratropic ring current passes the halogens as shown for $\mathrm{C}_{6} \mathrm{I}_{6}$ in Figure 1. The integrated current strength of $\mathrm{C}_{6} \mathrm{I}_{6}$ changes direction at about 1 A outside the $\mathrm{C}-\mathrm{C}$ bond.

The strength of the paratropic ring current passing the halogens is $-1.5 \mathrm{nA} / \mathrm{T}$ for $\mathrm{C}_{6} \mathrm{I}_{6}$ and $-3.3 \mathrm{nA} / \mathrm{T}$ for $\mathrm{C}_{6} \mathrm{At}_{6}$. For the molecules with heavier halogens, the orbital overlap of adjacent halogens is larger leading to less interference with the ring current in the carbon ring and a more benzene-like ring current in the carbon ring. For benzene, the ring current is $12.0 \mathrm{nA} / \mathrm{T}$ at the B3LYP/def2TZVP level as compared to the ring-current strength of $11.1 \mathrm{nA} / \mathrm{T}$ in the carbon ring of $\mathrm{C}_{6} \mathrm{At}_{6}$. The trends for $\operatorname{NICS}(1)_{z z}$ values in Table 2 are largely similar to the ones for the net ring-current strengths, whereas NICS(0) values are not a good measure of the aromaticity for this series mainly due to the exceptionally large NICS(0) value for $\mathrm{C}_{6} \mathrm{~F}_{6}$.

Table 2 Magnetically induced ring-current strengths $(\mathrm{J}$ in $\mathrm{nA} / \mathrm{T})$, and $\operatorname{NICS}(0)$ and NICS $(1)_{z z}$ values (in ppm) for neutral $\mathrm{C}_{6} \mathrm{X}_{6}$ calculated at the B3LYP/def2-TZVP level. The total ring-current strengths, the current strengths in the carbon ring $C_{6}$ and in the halogen ring $X_{6}$ as well as the paratropic and diatropic contributions to the net ring-current strengths are given.

\begin{tabular}{|c|c|c|c|c|c|c|c|}
\hline Molecule & Total & C6 & $\mathrm{X} 6$ & Dia & Para & $\operatorname{NICS}(0)$ & NICS $(1$ ) ring current strengths are $5.3 \mathrm{nA} / \mathrm{T}$ and $6.1 \mathrm{nA} / \mathrm{T}$, respectively \\
\hline $\mathrm{C}_{6} \mathrm{~F}_{6}$ & 9.7 & 9.4 & 0.3 & 12.6 & -2.9 & -17.6 & -23.2flowing mainly around the carbon ring. \\
\hline $\mathrm{C}_{6} \mathrm{Cl}_{6}$ & 9.0 & 8.1 & 0.9 & 13.5 & -4.5 & -9.2 & -19.2 For $\mathrm{C}_{6} \mathrm{Br}_{6}{ }^{2+}$ the triplet state is $66 \mathrm{~kJ} / \mathrm{mol}$ below the singlet. \\
\hline $\mathrm{C}_{6} \mathrm{Br}_{6}$ & 9.2 & 8.6 & 0.6 & 13.8 & -4.7 & -8.5 & $-18.6 \mathrm{The}$ ring-current strength of the triplet state is only $5.6 \mathrm{nA} / \mathrm{T}$ and \\
\hline $\mathrm{C}_{6} \mathrm{I}_{6}$ & 8.5 & 10.0 & -1.5 & 14.2 & -5.6 & -7.8 & -17.5 no ring current passes from $\mathrm{Br}$ to as for neutral $\mathrm{C}_{6} \mathrm{Br}_{6}$. The singlet \\
\hline $\mathrm{C}_{6} \mathrm{At}_{6}$ & 7.8 & 11.1 & -3.3 & 14.7 & -6.9 & -8.7 & $-17.1_{\text {state }}$ of $\mathrm{C}_{6} \mathrm{Br}_{6}{ }^{2+}$ sustain a strong ring current of $20.4 \mathrm{nA} / \mathrm{T}$ with \\
\hline
\end{tabular}

Table 3 Magnetically induced ring-current strengths ( $\mathrm{J}$ in $\mathrm{nA} / \mathrm{T})$, spin multiplicity $(2 \mathrm{~S}+1), \mathrm{NICS}(0)$ and $\mathrm{NICS}(1)_{z z}$ values (in ppm) for perhalogenated benzene cations calculated at the B3LYP/def2-TZVP level. The singlet-triplet energy splittings $\Delta E_{\mathrm{S}-\mathrm{T}}=E(S=1)-E(S=0)$ (in $\mathrm{eV})$ are also reported.

\begin{tabular}{lccccc}
\hline Molecule & $2 \mathrm{~S}+1$ & $\mathrm{~J}$ & $\mathrm{NICS}(0)$ & $\mathrm{NICS}(1)_{z z}$ & $\Delta E_{\mathrm{S}-\mathrm{T}}$ \\
\hline $\mathrm{C}_{6} \mathrm{~F}_{6}{ }^{2+}$ & 1 & -40.7 & 46.0 & 124.2 & 0.39 \\
$\mathrm{C}_{6} \mathrm{~F}_{6}{ }^{2+}$ & 3 & 6.1 & & & \\
$\mathrm{C}_{6} \mathrm{Cl}_{6}{ }^{2+}$ & 1 & 128.3 & -138.3 & -370.1 & 0.45 \\
$\mathrm{C}_{6} \mathrm{Cl}_{6}{ }^{2+}$ & 3 & 5.3 & & & \\
$\mathrm{C}_{6} \mathrm{Br}_{6}{ }^{2+}$ & 1 & 20.4 & -18.6 & -38.1 & 0.68 \\
$\mathrm{C}_{6} \mathrm{Br}_{6}{ }^{2+}$ & 3 & 5.6 & & & \\
$\mathrm{C}_{6} \mathrm{I}_{6}{ }^{2+}$ & 1 & 27.4 & -16.4 & -46.9 & -0.30 \\
$\mathrm{C}_{6} \mathrm{I}_{6}{ }^{+}$ & 2 & 18.2 & & & \\
$\mathrm{C}_{6} \mathrm{At}_{6}{ }^{2+}$ & 1 & 30.0 & -19.2 & -49.3 & -0.45 \\
\hline
\end{tabular}

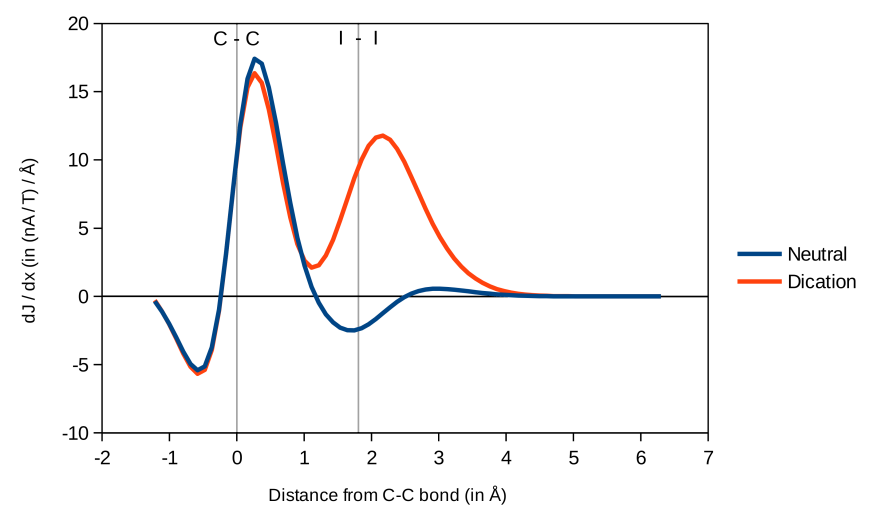

Fig. 1 Ring-current profiles for neutral and dicationic $C_{6} I_{6}$. The integration plane starts in the middle of the carbon ring. The positions of the $\mathrm{C}-\mathrm{C}$ bond and the I...I contact are marked in the graph.

The double aromatic character is illustrated in Figure 1, where the ring-current profile is plotted for neutral and dicationic $\mathrm{C}_{6} \mathrm{I}_{6}$. In $\mathrm{C}_{6} \mathrm{I}_{6}{ }^{2+}$, there is a strong diatropic current flowing around the molecular ring at the iodines, whereas neutral $\mathrm{C}_{6} \mathrm{I}_{6}$ sustains a paratropic ring-current in the vicinity of the iodines leading to a weaker net ring current as compared to benzene.

The ring-current strengths in the perhalogenated benzene dications are summarized in Table 3 . The current density for the perhalogenated dications are shown as vector plots in Figure 2. The signed modulus of the current densities are visualized in Figure 3. $\mathrm{C}_{6} \mathrm{I}_{6}{ }^{2+}$ and $\mathrm{C}_{6} \mathrm{At}_{6}{ }^{2+}$ sustain a strong diatropic ring current at the halogens, whose current strengths are $27.4 \mathrm{nA} / \mathrm{T}$ and $30.0 \mathrm{nA} / \mathrm{T}$, respectively. For $\mathrm{C}_{6} \mathrm{Cl}_{6}{ }^{2+}$ and $\mathrm{C}_{6} \mathrm{~F}_{6}{ }^{2+}$, the ring-current strength of the singlet state are $128.3 \mathrm{nA} / \mathrm{T}$ and $-40.7 \mathrm{nA} / \mathrm{T}$, respectively. However, $\mathrm{C}_{6} \mathrm{Cl}_{6}{ }^{2+}$ and $\mathrm{C}_{6} \mathrm{~F}_{6}{ }^{2+}$ has a triplet ground state, whose 
NICS $(1)_{z z}$ values can be used for estimating the degree of aromaticity of the singlet state of $\mathrm{C}_{6} \mathrm{Br}_{6}{ }^{2+}, \mathrm{C}_{6} \mathrm{I}_{6}{ }^{2+}$, and $\mathrm{C}_{6} \mathrm{I}_{6}{ }^{2+}$. For the dications, the correlation between $\operatorname{NICS}(1)_{z z}$ values and ringcurrent strengths is almost linear.

The current density was also calculated for $\mathrm{C}_{6} \mathrm{I}_{6}{ }^{+}$. The net ringcurrent strength is $18.2 \mathrm{nA} / \mathrm{T}$ consisting of the spin $\alpha$ contribution of $4.4 \mathrm{nA} / \mathrm{T}$ and a $\beta$ contribution of $13.8 \mathrm{nA} / \mathrm{T}$ yielding a spin current of $9.4 \mathrm{nA} / \mathrm{T}$. The spin current is the difference between the $\alpha$ and $\beta$ currents. The current density calculation suggest that $\mathrm{C}_{6} \mathrm{I}_{6}{ }^{+}$is also stabilized by aromaticity. The current densities are shown in Figure 4. The spin current is rather strong and localized to the outer current loop passing the iodine atoms showing that the unpaired electron is localized to the iodines. The ring currents in $\mathrm{C}_{6} \mathrm{I}_{6}{ }^{+}$and $\mathrm{C}_{6} \mathrm{I}_{6}{ }^{2+}$ consist of $9 \mathrm{nA} / \mathrm{T}$ in the carbon ring and 9 $\mathrm{nA} / \mathrm{T}$ per removed electron in the outer ring, adding up to 27 $\mathrm{nA} / \mathrm{T}$ for the $\mathrm{C}_{6} \mathrm{I}_{6}{ }^{2+}$.

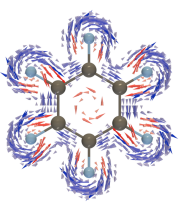

(a)

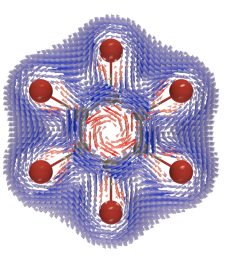

(d)

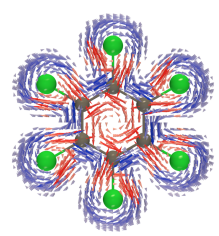

(b)

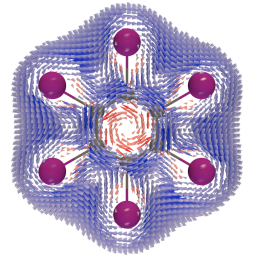

(e)

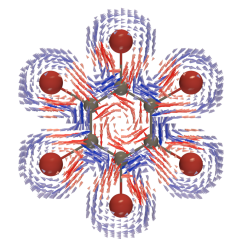

(c)

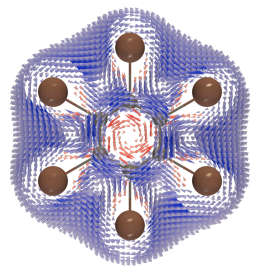

(f)
Fig. 2 Vector plots of the current density for the perhalogenated benzene dications $\mathrm{C}_{6} \mathrm{X}_{6}{ }^{2+}$ for various spin states calculated at the B3LYP/def2-TZVP level. a) $\mathrm{C}_{6} \mathrm{~F}_{6}{ }^{2+}(\mathrm{S}=1)$, b) $\mathrm{C}_{6} \mathrm{Cl}_{6}{ }^{2+}(\mathrm{S}=1)$, c) $\mathrm{C}_{6} \mathrm{Br}_{6}{ }^{2+}$ $(\mathrm{S}=1), \mathrm{d}) \mathrm{C}_{6} \mathrm{Br}_{6}{ }^{2+}(\mathrm{S}=0)$, e) $\left.\mathrm{C}_{6} \mathrm{I}_{6}{ }^{2+}(\mathrm{S}=0), \mathrm{f}\right) \mathrm{C}_{6} \mathrm{At}_{6}{ }^{2+}(\mathrm{S}=0)$. The diatropic current vectors are in blue and the paratropic ones in red. A factor of 10 Ang/a.u. is used to draw the vectors.

\section{Calculations on $\mathrm{C}_{6} \mathrm{X}_{6}$ and $\mathrm{C}_{6} \mathrm{X}_{6}{ }^{2+}, \mathrm{X}=\mathrm{SeH}$, $\mathrm{SeMe}, \mathrm{TeH}, \mathrm{TeMe}$, and $\mathrm{SbH}_{2}$}

\subsection{Molecular structures}

The optimised molecular structures show that the substituents of neutral $\mathrm{C}_{6}(\mathrm{SeMe})_{6}, \mathrm{C}_{6}(\mathrm{TeH})_{6}, \mathrm{C}_{6}(\mathrm{TeMe})_{6}$, and $\mathrm{C}_{6}\left(\mathrm{SbH}_{2}\right)_{6}$ are twisted out from the benzene plane with torsion angles of 10-33 degrees, whereas the corresponding dications are almost planar with torsion angles of 0-6 degrees. The torsion angles of the neutral and dicationic species are compared in Table 4. The twisted structure of the neutral molecules suggests that the interaction between the substituents is weak or repulsive due to steric effects, whereas the substituents in the dicationic species seem to interact.

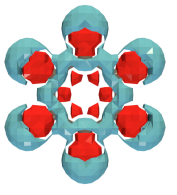

(a)

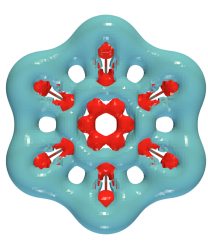

(d)

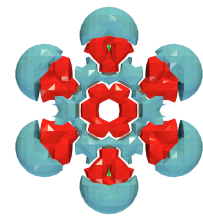

(b)

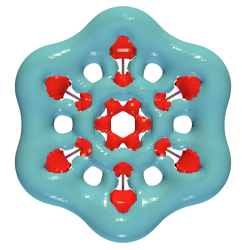

(e)

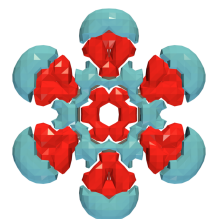

(c)

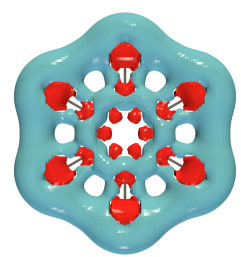

(f)
Fig. 3 Signed modulus of the current density for the perhalogenated benzene dications for various spin states calculated at the B3LYP/def2-TZVP level. a) $\mathrm{C}_{6} \mathrm{~F}_{6}{ }^{2+}(\mathrm{S}=1)$, b) $\mathrm{C}_{6} \mathrm{Cl}_{6}{ }^{2+}(\mathrm{S}=1)$, c) $\mathrm{C}_{6} \mathrm{Br}_{6}{ }^{2+}$ $(\mathrm{S}=1)$, d) $\mathrm{C}_{6} \mathrm{Br}_{6}{ }^{2+}(\mathrm{S}=0)$, e) $\left.\mathrm{C}_{6} \mathrm{I}_{6}{ }^{2+}(\mathrm{S}=0), \mathrm{f}\right) \mathrm{C}_{6} \mathrm{At}_{6}{ }^{2+}(\mathrm{S}=0)$. The diatropic current density is shown in turquoise and the paratropic one in red. The isosurface value is \pm 0.04 a.u.

Table 4 Average torsional angles (in degrees) for $\mathrm{C}_{6} \mathrm{X}_{6}$ and $\mathrm{C}_{6} \mathrm{X}_{6}{ }^{2+}$ with $\mathrm{X}=\mathrm{SeH}, \mathrm{SeMe}, \mathrm{TeH}, \mathrm{TeMe}$, and $\mathrm{SbH}_{2}$.

\begin{tabular}{lcccc}
\hline & \multicolumn{2}{c}{ Neutral } & \multicolumn{2}{c}{ Dication } \\
Molecule & C6 & X6 & C6 & X6 \\
\hline $\mathrm{C}_{6}(\mathrm{SeH})_{6}$ & 3.6 & 9.2 & 1.2 & 0.4 \\
$\mathrm{C}_{6}(\mathrm{SeMe})_{6}$ & 4.5 & 22.3 & 2.2 & 3.4 \\
$\mathrm{C}_{6}(\mathrm{TeH})_{6}$ & 4.9 & 33.3 & 0.9 & 6.4 \\
$\mathrm{C}_{6}(\mathrm{TeMe})_{6}$ & 4.8 & 30.9 & 1.2 & 4.4 \\
$\mathrm{C}_{6}\left(\mathrm{SbH}_{2}\right)_{6}$ & 2.4 & 28.7 & 1.5 & 2.8 \\
\hline
\end{tabular}

\subsection{Ring currents}

Current density calculations show that the substituents do not sustain any ring current in the outer part of neutral $\mathrm{C}_{6} \mathrm{X}_{6}$ with $\mathrm{X}=\mathrm{SeH}$, SeMe, $\mathrm{TeH}, \mathrm{TeMe}$, and $\mathrm{SbH}_{2}$, whereas the carbon rings sustain ring currents that are 1-3 nA/T weaker than for benzene. The calculated ring-current strengths are reported in Table 5.

The dications sustain ring currents in the carbon ring and around the exterior part of the molecule. The ring currents passing the substituents are strong in $\mathrm{C}_{6} \mathrm{X}_{6}{ }^{2+}$ with $\mathrm{X}=\mathrm{TeH}$, TeMe, and $\mathrm{SbH}_{2}$. For them, the total ring-current strengths are 33.2, 32.0, and $29.4 \mathrm{nA} / \mathrm{T}$, respectively, which are of the same size as for $\mathrm{C}_{6} \mathrm{I}_{6}{ }^{2+}$ and $\mathrm{C}_{6} \mathrm{At}_{6}{ }^{2+}$. The ring-current strengths of the cationic $\mathrm{C}_{6} \mathrm{X}_{6}{ }^{2+}$ species are summarized in Table 6 and the current densities are visualized in Figure 5.

The overlap between the orbitals of the substituents is smaller for $\mathrm{SeH}$ than for the heavier ones due to its smaller size. The ring current in the $\mathrm{C}_{6}(\mathrm{SeH})_{6}{ }^{2+}$ is therefore half as strong as for the dications with the larger substituents. The strong ring current also results in a more planar molecular structure. There is a practically linear relation between the $\operatorname{NICS}(1)_{z z}$ values and the ring-current strengths for this series of dicationic persubstituted benzenes, whereas for the corresponding neutral molecules, the 


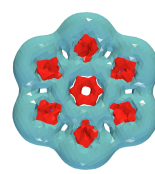

(a)

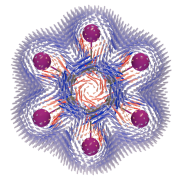

(e)

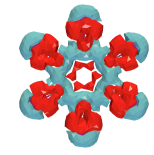

(b)

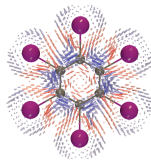

(f)

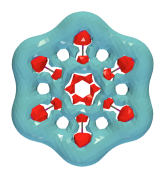

(c)

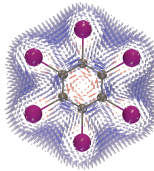

(g)

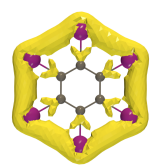

(d)
Fig. 4 Signed modulus (upper row) and vector plots (lower row) of the current density for the $\mathrm{C}_{6} \mathrm{I}_{6}{ }^{+}$cation calculated at the B3LYP/def2-TZVP level. a) total current density, b) $\alpha$ current density, c) $\beta$ current density, d) spin density, e) total current vector plot, f) $\alpha$ current vector plot, and g) $\beta$ current vector plot. The diatropic current density is shown in turquoise and paratropic one in red (a-c). In d, the spin current is shown in yellow. The isosurface value is \pm 0.02 a.u.. In the vector plots (e-g), diatropic current vectors are in blue and the paratropic ones in red. The current vectors are scaled with a factor of $15 \AA /$ a.u.

NICS $(1)_{z z}$ values cannot be used for estimating the degree of aromaticity. In that case, NICS $(1)_{z z}$ values provide only qualitative information about the molecular aromaticity. The doubly aromatic character of the dications can not be identified by calculating NICS(0) and NICS $(1)_{z z}$ values, whereas explicit integration and visualization of the current densities yield a detailed picture.

Table 5 Magnetically induced ring-current strengths $(\mathrm{J}$ in $n A / T)$, and $\operatorname{NICS}(0)$ and $\operatorname{NICS}(1)_{z z}$ values (in ppm) for $\mathrm{C}_{6} \mathrm{X}_{6}$ with $\mathrm{X}=\mathrm{SeH}$, SeMe, $\mathrm{TeH}, \mathrm{TeMe}$, and $\mathrm{SbH}_{2}$ calculated at the B3LYP/def2-TZVP level.

\begin{tabular}{lccc}
\hline Molecule & $\mathrm{J}$ & NICS $(0)$ & NICS $(1)_{z z}$ \\
\hline $\mathrm{C}_{6}(\mathrm{SeH})_{6}$ & 8.5 & -6.2 & -17.4 \\
$\mathrm{C}_{6}(\mathrm{SeMe})_{6}$ & 10.4 & -7.8 & -21.4 \\
$\mathrm{C}_{6}(\mathrm{TeH})_{6}$ & 10.6 & -7.3 & -23.2 \\
$\mathrm{C}_{6}(\mathrm{TeMe})_{6}$ & 11.2 & -7.9 & -22.0 \\
$\mathrm{C}_{6}\left(\mathrm{SbH}_{2}\right)_{6}$ & 9.9 & -5.5 & -20.4 \\
\hline
\end{tabular}

Table 6 Magnetically induced ring-current strengths $(\mathrm{J}$ in $\mathrm{nA} / \mathrm{T})$, and $\operatorname{NICS}(0)$ and NICS $(1)_{z z}$ values (in ppm) for $\mathrm{C}_{6} \mathrm{X}_{6}{ }^{2+}$ with $\mathrm{X}=\mathrm{SeH}$, SeMe, $\mathrm{TeH}, \mathrm{TeMe}$, and $\mathrm{SbH}_{2}$ calculated at the B3LYP/def2-TZVP level.

\begin{tabular}{lccc}
\hline Molecule & $\mathrm{J}$ & NICS $(0)$ & NICS $(1)_{z z}$ \\
\hline $\mathrm{C}_{6}(\mathrm{SeH})_{6}{ }^{2+}$ & 16.6 & -9.3 & -26.8 \\
$\mathrm{C}_{6}(\mathrm{SeMe})_{6}{ }^{2+}$ & 24.5 & -16.1 & -44.5 \\
$\mathrm{C}_{6}(\mathrm{TeH})_{6}{ }^{2+}$ & 33.2 & -21.0 & -56.9 \\
$\mathrm{C}_{6}(\mathrm{TeMe})_{6}{ }^{2+}$ & 32.0 & -20.6 & -55.2 \\
$\mathrm{C}_{6}\left(\mathrm{SbH}_{2}\right)_{6}{ }^{2+}$ & 29.4 & -18.7 & -49.1 \\
\hline
\end{tabular}

\section{$5 \quad$ ECPs and relativity}

The Stuttgart ECPs have been used for I and At. Since this is the first time that ECPs have been used in combination with GIMIC calculations, we checked whether the ring-current strengths are

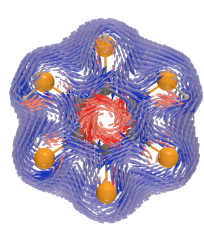

(a)

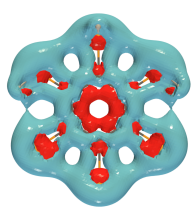

(d)

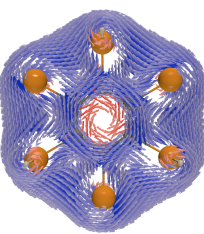

(b)

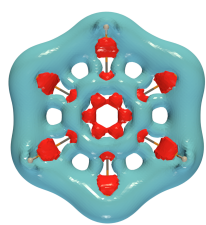

(e)

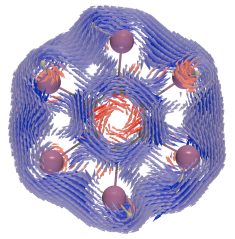

(c)

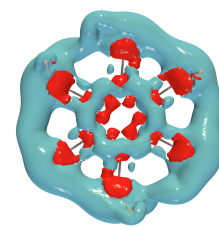

(f)
Fig. 5 Vector plots (upper row) and signed modulus (lower row) of the current density for $\mathrm{C}_{6}(\mathrm{SeH})_{6}{ }^{2+}$, (a and d) $\mathrm{C}_{6}(\mathrm{TeH})_{6}{ }^{2+}(\mathrm{b}$ and $\mathrm{e})$, and $\mathrm{C}_{6}\left(\mathrm{SbH}_{2}\right)_{6}{ }^{2+}$ (c and f) calculated at the B3LYP/def2-TZVP level. In the vector plots $(\mathrm{a}-\mathrm{c})$, the diatropic current vectors are in blue and the paratropic ones in red. The current vectors are scaled with a factor of 15 $\AA$ A/a.u.. The diatropic current density is shown in turquoise and paratropic one in red (d-f). The isosurface value is \pm 0.04 a.u.

affected by approximating the core electrons with ECPs. Allelectron calculations at the B3LYP level using a triple-zeta quality basis, as described in Computational Methods, yield a ring current of $29.2 \mathrm{nA} / \mathrm{T}$ for $\mathrm{C}_{6} \mathrm{At}_{6}{ }^{2+}$ and $7.2 \mathrm{nA} / \mathrm{T}$ for the corresponding neutral molecule. The ring-current strengths obtained using the non-relativistic 78-electron core ECP78MHF, thus considering only 7 valence electrons, are 29.7 and $7.6 \mathrm{nA} / \mathrm{T}$. The ECP calculations yield current strengths that are only $1.7 \%$ and $5.6 \%$ larger than obtained with the all-electron treatment showing that current densities can be calculated using ECPs.

Relativistic effects are usually included in the ECPs. Thus, scalar relativistic effects on the current densities can be estimated by employing ECPs. Spin-orbit coupling (SOC) is not taken into account. However, a recent current-density study on gold and mercury hydrides by Berger et al. showed that SOC effects did not qualitatively change the current density, ${ }^{50}$ whereas SOC effects introduces current-density cusps at the protons adjacent to the heavy atoms.

Table 7 summarizes the ring-current strengths obtained using the non-relativistic, quasi-relativistic and fully relativistic ECPs. For I, a small-core ECP with 28 electrons and a large-core ECP with 46 electrons were used. The large and small core ECPs treat relativity differently implying that the effect of the employed core size cannot be deduced from a comparison of the obtained ringcurrent strengths. However, since the current strengths obtained in the all-electron and ECP calculation agree well, the difference in the current strengths obtained with the small- and large-core ECPs must be assigned to their ability to consider relativistic effects and core electrons.

Relativistic effects can be estimated for $\mathrm{C}_{6} \mathrm{At}_{6}$ and $\mathrm{C}_{6} \mathrm{At}_{6}{ }^{2+}$ by comparing current strengths obtained with the relativistic and non-relativistic ECPs. The calculations show that scalar relativistic effects reduce the total ring-current strength of $\mathrm{C}_{6} \mathrm{Al}_{6}{ }^{2+}$ by 
Table 7 Magnetically induced ring-current strengths ( $\mathrm{J}$ in $\mathrm{nA} / \mathrm{T}$ ) for $\mathrm{C}_{6} \mathrm{I}_{6}{ }^{2+}, \mathrm{C}_{6} \mathrm{At}_{6}$, and $\mathrm{C}_{6} \mathrm{At}_{6}{ }^{2+}$ calculated at the B3LYP level using the def2-TZVP basis set for $C$ and the Stuttgart ECP basis sets for I and At Abbreviations NR, QR, or FR stand for non-relativistic, quasi-relativistic, and fully relativistic ECPs. Details are described in the Computational Methods section.

\begin{tabular}{lcccc}
\hline Molecule & Rel & ECP & Valence & $\mathrm{J}$ \\
\hline $\mathrm{C}_{6} \mathrm{I}_{6}{ }^{2+}$ & $\mathrm{NR}$ & $\mathrm{AE}$ & $\mathrm{TZ}$ & 26.5 \\
$\mathrm{C}_{6} \mathrm{I}_{6}{ }^{2+}$ & $\mathrm{FR}$ & ECP28MDF & $\mathrm{TZ}$ & 27.2 \\
$\mathrm{C}_{6} \mathrm{I}_{6}{ }^{2+}$ & $\mathrm{FR}$ & ECP28MDF & $\mathrm{QZ}$ & 27.2 \\
$\mathrm{C}_{6} \mathrm{I}_{6}{ }^{2+}$ & $\mathrm{QR}$ & ECP46MWF & $\mathrm{TZ}$ & 29.9 \\
$\mathrm{C}_{6} \mathrm{I}_{6}{ }^{2+}$ & $\mathrm{QR}$ & $\mathrm{ECP46MWF}$ & $\mathrm{QZ}$ & 29.5 \\
$\mathrm{C}_{6} \mathrm{At}_{6}{ }^{2+}$ & $\mathrm{NR}$ & $\mathrm{AE}$ & $\mathrm{DZ}$ & 29.2 \\
$\mathrm{C}_{6} \mathrm{At}_{6}{ }^{2+}$ & $\mathrm{NR}$ & $\mathrm{ECP78MHF}$ & $\mathrm{DZ}$ & 29.7 \\
$\mathrm{C}_{6} \mathrm{At}_{6}{ }^{2+}$ & $\mathrm{FR}$ & $\mathrm{ECP78MDF}$ & $\mathrm{DZ}$ & 28.5 \\
$\mathrm{C}_{6} \mathrm{At}_{6}$ & $\mathrm{NR}$ & $\mathrm{AE}$ & $\mathrm{DZ}$ & 7.2 \\
$\mathrm{C}_{6} \mathrm{At}_{6}$ & $\mathrm{NR}$ & $\mathrm{ECP78MHF}$ & $\mathrm{DZ}$ & 7.6 \\
$\mathrm{C}_{6} \mathrm{At}_{6}$ & $\mathrm{FR}$ & $\mathrm{ECP78MDF}$ & $\mathrm{DZ}$ & 9.1 \\
\hline
\end{tabular}

$4.0 \%(1.2 \mathrm{nA} / \mathrm{T})$ and it increases the ring current strength of $\mathrm{C}_{6} \mathrm{At}_{6}$ by $19.7 \%(1.5 \mathrm{nA} / \mathrm{T})$.

\section{Conclusions}

The GIMIC method has been interfaced to the Gaussian program rendering calculations of magnetically induced current densities for molecules whose core electrons are replaced with ECPs possible. In addition, magnetically induced current-density calculations can also be performed at the DFT level on open-shell molecules. Current-density calculations on $\mathrm{C}_{6} \mathrm{At}_{6}$ and $\mathrm{C}_{6} \mathrm{At}_{6}{ }^{2+}$ using non-relativistic ECPs yield ring-current strengths that agree well with the ones obtained in the all-electron calculations suggesting that ECP calculations can be used in current-density calculations. The close agreement between the current densities obtained in the all-electron and ECP calculations shows that ring currents mainly involve the valence electrons.

Integration of the current density passing selected planes through the molecular rings show that the previously suggested double aromaticity of $\mathrm{C}_{6} \mathrm{I}_{6}{ }^{2+}$ also exists for $\mathrm{C}_{6} \mathrm{At}_{6}{ }^{2+}$, and $\mathrm{C}_{6} \mathrm{X}_{6}{ }^{2+}$ with $\mathrm{X}=\mathrm{SeH}$, SeMe, TeH, TeMe, and $\mathrm{SbH}_{2}$. For these dications, the net ring-current strengths are $17-33 \mathrm{nA} / \mathrm{T}$, which is about 1.52.5 times the benzene value of $12.0 \mathrm{nA} / \mathrm{T}$. The singlet state of $\mathrm{C}_{6} \mathrm{Br}_{6}{ }^{2+}$ also sustains a strong ring current. However, the triplet state is its ground state that sustains a weak ring current of 5.6 $\mathrm{nA} / \mathrm{T}$ in the carbon ring. Thus, the ground state of $\mathrm{C}_{6} \mathrm{Br}_{6}{ }^{2+}$ is not doubly aromatic. The same holds for $\mathrm{C}_{6} \mathrm{~F}_{6}{ }^{2+}$ and $\mathrm{C}_{6} \mathrm{Cl}_{6}{ }^{2+}$. Current density calculations on $\mathrm{C}_{6} \mathrm{I}_{6}{ }^{+}$shows that it is also doubly aromatic as the corresponding dication. However, the ringcurrent strength of $\mathrm{C}_{6} \mathrm{I}_{6}{ }^{+}$in the exterior part of the molecule is is only half as strong as the one passing the iodines in $\mathrm{C}_{6} \mathrm{I}_{6}{ }^{2+}$.

The effect of scalar relativity on the ring-current strengths for $\mathrm{C}_{6} \mathrm{At}_{6}{ }^{2+}$ and $\mathrm{C}_{6} \mathrm{At}_{6}$ of less than $2 \mathrm{nA} / \mathrm{T}$ is rather small. However, since the ring-current strength of the neutral $\mathrm{C}_{6} \mathrm{At}_{6}$ is only $7.6 \mathrm{nA} / \mathrm{T}$, the scalar relativistic effects increase the ring current strength by $20 \%$. The ring-current strength of $\mathrm{C}_{6} \mathrm{At}_{6}{ }^{2+}$ obtained in the non-relaticistic and relativistic calculations are 29.7 $\mathrm{nA} / \mathrm{T}$ and $28.5 \mathrm{nA} / \mathrm{T}$, respectively, implying that relativistic effects amount to only 4\%. Spin-orbit coupling effects have not been considered.

\section{Acknowledgements}

This work has been supported by the Academy of Finland through projects 268251 (ST), 289179 (MR) and 275845 (DS). ST thanks the University of Namur for supporting a short term visit. CSC the Finnish IT Center for Science is acknowledged for computer time. V.L. thanks the Fund for Scientific Research (FRS.-FNRS) for his Research Associate position.

\section{References}

1 D. Sagl and J. Martin, J. Am. Chem. Soc., 1988, 110, 58275833.

2 E. Wasserman, R. S. Hutton, V. J. Kuck and E. A. Chandross, J. Am. Chem. Soc., 1974, 96, 1965-1966.

3 M. J. Molski, D. Mollenhauer, S. Gohr, B. Paulus, M. A. Khanfar, H. Shorafa, S. H. Strauss and K. Seppelt, Chem. Eur. J., 2012, 18, 6644-6654.

4 M. J. Molski, M. A. Khanfar, H. Shorafa and K. Seppelt, Eur. J. Org. Chem., 2013, 2013, 3131-3136.

5 I. Ciofini, P. P. Lainé and C. Adamo, Chem. Phys. Lett., 2007, 435, 171-175.

6 R. W. A. Havenith, P. W. Fowler, S. Fias and P. Bultinck, Tetrahedron Lett., 2008, 49, 1421-1424.

7 M. Hatanaka, M. Saito, M. Fujita and K. Morokuma, J. Org. Chem., 2014, 79, 2640-2646.

8 J. Jusélius, D. Sundholm and J. Gauss, J. Chem. Phys., 2004, 121, 3952-3963.

9 S. Taubert, D. Sundholm and J. Jusélius, J. Chem. Phys., 2011, 134, 054123.

10 D. Sundholm, H. Fliegl and R. J. F. Berger, WIREs Comput Mol Sci, 2016, 6, 639-678.

11 J. A. Pople, Mol. Phys., 1958, 1, 175-180.

12 R. McWeeny, Mol. Phys., 1958, 1, 311-321.

13 P. Lazzeretti, Prog Nucl Mag Res Sp, 2000, 36, 1-88.

14 H. Fliegl, D. Sundholm, S. Taubert, J. Jusélius and W. Klopper, J. Phys. Chem. A, 2009, 113, 8668-8676.

15 Z. Rinkevicius, J. Vaara, L. Telyatnik and O. Vahtras, J. Chem. Phys., 2003, 118, 2550-2561.

16 R. Ahlrichs, M. Bär, M. Häser, H. Horn and C. Kölmel, Chem. Phys. Lett., 1989, 162, 165-169.

17 F. Furche, R. Ahlrichs, C. Hättig, W. Klopper, M. Sierka and F. Weigend, WIREs Comput Mol Sci, 2014, 4, 91-100.

18 J. F. Stanton, J. Gauss, M. E. Harding and P. G. Szalay, CFOUR, Coupled Cluster techniques for Computational Chemistry, a quantum-chemical program package also with contributions from A.A. Auer, R. J. Bartlett, U. Benedikt, C. Berger, D. E. Bernholdt, Y. J. Bomble, O. Christiansen, M. Heckert, O. Heun, C. Huber, T-C. Jagau, D. Jonsson, J. Jusélius, K. Klein, W. J. Lauderdale, D. A. Matthews, T. Metzroth, D. P. O'Neill, D. R. Price, E. Prochnow, K. Ruud, F. Schiffmann, S. Stopkowicz, M. E. Varner, J. Vázquez, F. Wang, J. D. Watts and the integral packages MOLECULE (J. Almlöf and P. R. Taylor), PROPS 
(P. R. Taylor), ABACUS (T. Helgaker, H. J. Aa. Jensen, P. Jørgensen, and J. Olsen), and ECP routines by $A$. V. Mitin and $C$. van Wüllen. For the current version, see http://www.cfour.de., 2009.

19 A. D. Becke, J. Chem. Phys., 1993, 98, 5648-5652.

20 C. Lee, W. Yang and R. G. Parr, Phys. Rev. B, 1988, 37, 785789.

21 O. Treutler and R. Ahlrichs, J. Chem. Phys., 1995, 102, 346354.

22 K. Eichkorn, O. Treutler, H. Öhm, M. Häser and R. Ahlrichs, Chem. Phys. Lett., 1995, 240, 283-290.

23 K. Eichkorn, O. Treutler, H. Öhm, M. Häser and R. Ahlrichs, Chem. Phys. Lett., 1995, 242, 652-660.

24 K. Eichkorn, F. Weigend, O. Treutler and R. Ahlrichs, Theoret. Chem. Acc., 1997, 97, 119-124.

25 F. Weigend and R. Ahlrichs, Phys. Chem. Chem. Phys., 2005, 7, 3297-3305.

26 M. J. Frisch, G. W. Trucks, H. B. Schlegel, G. E. Scuseria, M. A. Robb, J. R. Cheeseman, G. Scalmani, V. Barone, B. Mennucci, G. A. Petersson, H. Nakatsuji, M. Caricato, X. Li, H. P. Hratchian, A. F. Izmaylov, J. Bloino, G. Zheng, J. L. Sonnenberg, M. Hada, M. Ehara, K. Toyota, R. Fukuda, J. Hasegawa, M. Ishida, T. Nakajima, Y. Honda, O. Kitao, H. Nakai, T. Vreven, J. A. Montgomery, Jr., J. E. Peralta, F. Ogliaro, M. Bearpark, J. J. Heyd, E. Brothers, K. N. Kudin, V. N. Staroverov, R. Kobayashi, J. Normand, K. Raghavachari, A. Rendell, J. C. Burant, S. S. Iyengar, J. Tomasi, M. Cossi, N. Rega, J. M. Millam, M. Klene, J. E. Knox, J. B. Cross, V. Bakken, C. Adamo, J. Jaramillo, R. Gomperts, R. E. Stratmann, O. Yazyev, A. J. Austin, R. Cammi, C. Pomelli, J. W. Ochterski, R. L. Martin, K. Morokuma, V. G. Zakrzewski, G. A. Voth, P. Salvador, J. J. Dannenberg, S. Dapprich, A. D. Daniels, Ö. Farkas, J. B. Foresman, J. V. Ortiz, J. Cioslowski and D. J. Fox, Gaussian 09 Revision E.01, Gaussian Inc. Wallingford CT 2009.

27 A. D. Becke, Phys. Rev. A, 1988, 38, 3098-3100.

28 J. P. Perdew, Phys. Rev. B, 1986, 33, 8822-8824.

29 J. P. Perdew, K. Burke and M. Ernzerhof, Phys. Rev. Letters, 1996, 77, 3865-3868.

30 J. P. Perdew and Y. Wang, Phys. Rev. B, 1992, 45, 1324413249.

31 C. Lee, W. Yang and R. G. Parr, Phys. Rev. B, 1988, 37, 785-
789.

32 A. D. Becke, J. Chem. Phys., 1993, 98, 5648-5652.

33 J. P. Perdew, K. Burke and M. Ernzerhof, J. Chem. Phys., 1996, 105, 9982-9985.

34 A. D. Becke, J. Chem. Phys., 1993, 98, 1372-1377.

35 ECP basis sets for I and At were obtained from http://www.tc.uni-koeln.de/PP/clickpse.en.html.

36 K. A. Peterson, B. C. Shepler, D. Figgen and H. Stoll, J. Phys. Chem. A, 2006, 110, 13877-13883.

37 A. Bergner, M. Dolg, W. Kuechle, H. Stoll and H. Preuss, Mol. Phys., 1993, 80, 1431-1441.

38 H. Stoll, B. Metz and M. Dolg, J. Comput. Chem., 2002, 23, 767-778.

39 W. Kuechle, M. Dolg, H. Stoll and H. Preuss, Mol. Phys, 1991, 74, 1245-1263.

40 K. A. Peterson, B. C. Shepler, D. Figgen and H. Stoll, J. Phys. Chem. A, 2006, 110, 13877-13883.

41 W. Küchle, M. Dolg, H. Stoll and H. Preuss, Mol. Phys., 1991, 74, 1245-1263.

42 L. Martins, F. de Souza, G. Ceolin, F. Jorge, R. de Berredo and C. Campos, Comput. Theor. Chem., 2013, 1013, 62-69.

43 P. von Ragué Schleyer, C. Maerker, A. Dransfeld, H. Jiao and N. J. R. van Eikema Hommes, J. Am. Chem. Soc., 1996, 118, 6317-6318.

44 Z. Chen, C. S. Wannere, C. Corminboeuf, R. Puchta and P. von Ragué Schleyer, Chem. Rev., 2005, 105, 3842-3888.

45 DrawMol, a graphical interface to visualize and build molecular structures, Vincent Liégeois, UNamur, http://www.unamur.be/drawmol.

46 T. Helgaker, P. Jørgensen and J. Olsen, Molecular electronicstructure theory, Wiley, Chichester; New York, 2000.

47 H. B. Schlegel and M. J. Frisch, Int. J. Quantum Chem., 1995, 54, 83-87.

48 M. Kaipio, M. Patzschke, H. Fliegl, F. Pichierri and D. Sundholm, J. Phys. Chem. A, 2012, 116, 10257-10268.

49 J. J. Torres-Vega, A. Vásquez-Espinal, L. Ruiz, M. A. Fernández-Herrera, L. Alvarez-Thon, G. Merino and W. Tiznado, ChemistryOpen, 2015, 4, 302-307.

50 R. J. F. Berger, M. Repisky and S. Komorovsky, Chem. Commun., 2015, 51, 13961-13963. 